Comment

\title{
Comment on Wunsch et al. The Impact of COVID-19 on the Interrelation of Physical Activity, Screen Time and Health-Related Quality of Life in Children and Adolescents in Germany: Results of the Motorik-Modul Study. Children $2021,8,98$
}

\author{
Mathilde Kersting ${ }^{1, *}$, Hermann Kalhoff ${ }^{1,2}$ (D) and Thomas Lücke ${ }^{1,3}$ \\ 1 Research Department of Child Nutrition (FKE), Pediatric University Clinic, Ruhr-University, \\ D-44791 Bochum, Germany; Hermann.Kalhoff@klinikumdo.de (H.K.); \\ luecke.thomas@ruhr-uni-bochum.de (T.L.) \\ 2 Pediatric Clinic Dortmund, D-44137 Dortmund, Germany \\ 3 Pediatric University Clinic, Medical School, Ruhr-University, D-44791 Bochum, Germany \\ * Correspondence: mathilde.kersting@ruhr-uni-bochum.de
}

Citation: Kersting, M.; Kalhoff, $\mathrm{H}$.; Lücke, T. Comment on Wunsch et al. The Impact of COVID-19 on the Interrelation of Physical Activity, Screen Time and Health-Related Quality of Life in Children and Adolescents in Germany: Results of the Motorik-Modul Study. Children 2021, 8, 98. Children 2021, 8, 520. https://doi.org/10.3390/

children 8060520

Received: 1 March 2021

Accepted: 16 June 2021

Published: 18 June 2021

Publisher's Note: MDPI stays neutral with regard to jurisdictional claims in published maps and institutional affiliations.

Copyright: (c) 2021 by the authors. Licensee MDPI, Basel, Switzerland. This article is an open access article distributed under the terms and conditions of the Creative Commons Attribution (CC BY) license (https:// creativecommons.org/licenses/by/ $4.0 /)$.
A recent study concerning the "Impact of COVID-19 on the Interrelation of Physical Activity, Screen Time and Health-Related Quality of Life in Children and Adolescents in Germany" was investigated by Wunsch et al. [1]. To assess adolescents' subjective health and well-being, the KIDSCREEN-10 index [2] was used, a short-form of the KIDSCREEN27. Intuitively, one would assume that dietary behaviour is as important a predictor of health-related quality of life (HRQoL) as physical activity and screen time.

A total of 10 dimensions of HRQoL are considered in the basic KIDSCREE ${ }^{\prime} \mathrm{N}$ 52: physical well-being, psychological well-being, moods and emotions, self-perception, autonomy, parent relations and home life, social support and peers, school environment, social acceptance (bullying), and financial resources. KIDSCREEN-27 and KIDSCREEN-10 consist of five dimensions thereof (Available online: https: / / www.kidscreen.org/english/ questionnaires/kidscreen-52-long-version/, accessed on 22 February 2021).

For nutritionists and paediatricians, nutrition is one further dimension with the potential to have a fundamentally positive impact on quality of life, especially for children. In addition to the direct impact of food on physical health and well-being, we include various positive (hedonic) sensations associated with food intake, among them sensory perceptions such as taste and smell, and increasing feelings of satiety. As is well-known, presentation and visual impact also play an important role in the pleasure of eating, especially for children, and not least the social environment of eating with the family or with friends at school.

The burning glass nature of the Coronavirus pandemic may be an opportunity to re-evaluate the contribution of nutrition to the health-related quality of life in children.

Author Contributions: Conceptualization, M.K. and H.K.; resources, T.L.; writing-original draft preparation, M.K. and H.K.; writing-review and editing, M.K., H.K. and T.L. All authors have read and agreed to the published version of the manuscript.

Funding: This research received no external funding.

Informed Consent Statement: Not applicable.

Data Availability Statement: Data sharing not applicable.

Conflicts of Interest: The authors declare no conflict of interest. 


\section{References}

1. Wunsch, K.; Nigg, C.; Niessner, C.; Schmidt, S.C.E.; Oriwol, D.; Hanssen-Doose, A.; Burchartz, A.; Eichsteller, A.; Kolb, S.; Worth, A.; et al. The Impact of COVID-19 on the Interrelation of Physical Activity, Screen Time and Health-Related Quality of Life in Children and Adolescents in Germany: Results of the Motorik-Modul Study. Children 2021, 8, 98. [CrossRef] [PubMed]

2. Ravens-Sieberer, U.; Herdman, M.; Devine, J.; Otto, C.; Bullinger, M.; Rose, M.; Klasen, F. The European KIDSCREEN approach to measure quality of life and well-being in children: Development, current application, and future advances. Qual. Life Res. 2014, 23, 791-803. [CrossRef] [PubMed] 